\title{
The Effect of Sodium Gluconate on Pastes' Performance and Hydration Behavior of Ordinary Portland Cement
}

\author{
Xingdong Lv (iD, ${ }^{1,2}$ Jiazheng Li, ${ }^{1}$ Chao Lu, ${ }^{3}$ Zhanao Liu, ${ }^{4}$ Yaosheng Tan, ${ }^{4}$ Chunfeng Liu, ${ }^{4}$ \\ Beixing Li, ${ }^{2}$ and Rongkai Wang ${ }^{1}$ \\ ${ }^{1}$ Changjiang River Scientific Research Institute of Changjiang Water Resources Commission, Wuhan 430010, China \\ ${ }^{2}$ State Key Laboratory of Silicate Materials for Architecture, Wuhan University of Technology, Wuhan 430070, China \\ ${ }^{3}$ China Three Gorges Corporation, Beijing 100036, China \\ ${ }^{4}$ Baihetan Project Construction Department, China Three Gorges Projects Development Co., Ltd., Liangshan 615421, \\ Sichuan, China \\ Correspondence should be addressed to Xingdong Lv; 1115650343@qq.com
}

Received 30 August 2019; Revised 5 December 2019; Accepted 1 February 2020; Published 20 February 2020

Academic Editor: Victor M. Castaño

Copyright ( 2020 Xingdong Lv et al. This is an open access article distributed under the Creative Commons Attribution License, which permits unrestricted use, distribution, and reproduction in any medium, provided the original work is properly cited.

\begin{abstract}
The goal of this paper provides better understanding of the effect of sodium gluconate (SG) on ordinary Portland cement (OPC) hydration behavior. Pastes' performances of ordinary Portland cement, including setting time at $20^{\circ} \mathrm{C}$ and $35^{\circ} \mathrm{C}$ curing temperature, mechanical strength, fluidity, and zeta potential are studied. Furthermore, the effects of SG on cement hydration behaviors are investigated by the means of isothermal calorimetry measurements, X-ray diffraction (XRD), and thermogravimetric analysis (TGA). The results show that SG is difficult to maintain significant retarding effect at the temperature of $35^{\circ} \mathrm{C}$ compared to that at the temperature of $20^{\circ} \mathrm{C}$. SG is able to reduce the cement cumulative hydration heat and delay the occurrence time of heat evolution peak in a certain extent, but it has little impact on reducing the cement evolution rate peak. The effects of SG on mechanical properties and dispersion properties of cement depend on its dosages. Specifically, the positive effect occurs when the addition dosage is less than $0.15 \%$ (i.e., by cement weight), but the negative effect emerges if the addition dosages exceed this limitation. Similarly, SG plays different roles on cement hydration at different hydration periods. It inhibits the hydration of $\mathrm{C}_{3} \mathrm{~S}$ and the formation of portlandite $(\mathrm{CH})$ at the early hydration period. On the contrary, it promotes the $\mathrm{C}_{3} \mathrm{~S}$ hydration when hydration time is beyond $1 \mathrm{~d}$. Meanwhile, SG also plays different roles on cement hydration at different dosage additions. Specifically, SG promotes ettringite (AFt) formation at the dosage less than $0.06 \%$, but it inhibits AFt formation at the dosage more than $0.06 \%$.
\end{abstract}

\section{Introduction}

The setting and hardening behaviors of cement are controlled by the addition of different retarding and accelerating admixtures, which is very commonly used in real concrete engineering [1]. The retarding admixtures can be classified to inorganic and organic admixtures according to their basic materials [2]. Inorganic retarding admixtures include phosphates, borates fluorine silicates, and chemical compounds based on zinc $[3,4]$. Organic retarders include saccharides, ligninsulfonate, hydroxycarboxylic acid, and their salts [5]. SG is one kind of typical hydroxycarboxylic acid salt [6]. SG is commonly used in real concrete projects, which ascribes the significant retarding effect, good adaptability with superplasticizer system, and economic price $[7,8]$.

Many studies of the effects of SG on cement pastes' dispersion and strength development are displayed in this paper [9]. According to $\mathrm{Li}$ et al. [10], the compressive strengths of cement mortars generate reduction at different degrees in the case of addition dosages ranging from $0.03 \%$ to $0.15 \%$. Ma et al. [11] proposed that the appropriate amount of SG can further improve the dispersion performance of cement pastes mixed with polycarboxylate superplasticizer (PCE) significantly. Meanwhile, some 
studies point out that the effect of SG on the performance and hydration process of cement pastes are depending on its addition dosages. Tan et al. [12] suggests that the dispersion of PCE-SG system depends on the predominant effect, i.e., the contribution to dispersion predominates, at the dosage of SG less than $0.10 \%$. However, the competitive adsorption effect predominates at the dosage more than $0.10 \%$, resulting in declining dispersion ability. Ma et al. $[13,14]$ regarded as SG promoting the formation of AFt at early hydration time when the dosage was less than $0.03 \%$. On the contrary, SG inhibits the formation of AFt when the dosage was more than $0.05 \%$.

The effects of SG on cement hydration behaviors and retarding mechanism have not been fully understood, and several studies are mentioned in this paper [15]. Zhang et al. [16] suggested SG firstly, delaying AFt formation slightly and then promoting the AFt formation once it begins to form. According to Perez [17], SG can be absolutely adsorbed on $\mathrm{C}_{3} \mathrm{~S}$ surfaces, resulting in a severe inhibition of hydration. SG mainly delays the hydration of $\mathrm{C}_{3} \mathrm{~S}$, which prolongs the induction period. vonDaake and Stephan [18] regarded $\mathrm{CH}$ and $\mathrm{C}-\mathrm{S}-\mathrm{H}$ formations are significantly influenced by SG dosages, whereas the renewing hydration reaction proceeds faster after the end of the induction period. Ma et al. and Wu et al. [19,20] suggested that SG delays the cement induction period, whereas it accelerates the hydration of $\mathrm{C}_{3} \mathrm{~S}$ in the hydration acceleration period.

The previous studies discussed the setting behaviors of cement added with SG almost at a normal temperature, but the setting behaviors at higher temperature are less investigated. In addition, the hydration behavior of SG on Portland cement is still not conclusive. The effect of SG on different cement minerals is also not conclusive. This paper provides better understanding of the effect of SG on OPC hydration behavior, which include the retarding effect of SG on cement at higher temperature, the effect of different dosages addition of SG on cement hydration, and the effect of SG on different cement mineral hydration. The effect of SG on cement setting time, mechanical strength, fluidity, and zeta potential is studied. Besides, the effects of SG on cement hydration behavior are investigated by the means of isothermal calorimetry measurements, XRD, and TGA.

\section{Experimental}

2.1. Materials. The purity of SG (commercially available) is $99 \%$, the molecular formula is $\mathrm{C}_{6} \mathrm{H}_{11} \mathrm{NaO}_{7}$, and the structural formula is given in Figure 1. The solid content of PCE (commercially available) is $40 \%$. The chemical of OPC and the content of cement clinkers are shown in Tables 1 and 2, respectively. The main chemical composition of cement and SF were determined by X-ray fluorescence (XRF). XRF data were collected by Zetium manufactured from Panalytical.B.V, Netherlands, in which the power of rhodium target window $\mathrm{X}$-ray tube is $4 \mathrm{kw}$. And the cement clinker data are supplied by the manufacturer.

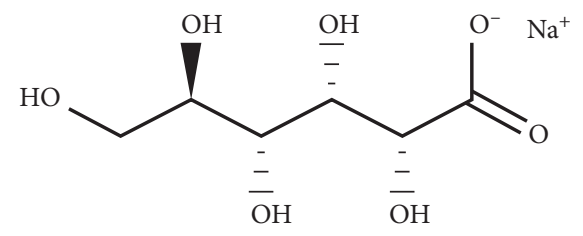

FIGURE 1: Structural formula of SG.

Table 1: Chemical composition of OPC (wt.\%).

\begin{tabular}{llllllllll}
\hline $\mathrm{SiO}_{2}$ & $\mathrm{CaO}$ & $\mathrm{Al}_{2} \mathrm{O}_{3}$ & $\mathrm{Fe}_{2} \mathrm{O}_{3}$ & $\mathrm{MgO}$ & $\begin{array}{c}\mathrm{f}- \\
\mathrm{CaO}\end{array}$ & $\mathrm{SO}_{3}$ & $\mathrm{~K}_{2} \mathrm{O}$ & $\mathrm{Na}_{2} \mathrm{O}$ & Loss* \\
\hline 21.02 & 61.41 & 4.80 & 3.68 & 1.03 & 0.97 & 2.02 & 0.60 & 0.02 & 3.78 \\
\hline
\end{tabular}

${ }^{*}$ Loss on ignition of cement.

TABle 2: The content of cement clinkers (wt.\%).

\begin{tabular}{lccc}
\hline $\mathrm{C}_{3} \mathrm{~S}$ & $\mathrm{C}_{2} \mathrm{~S}$ & $\mathrm{C}_{3} \mathrm{~A}$ & $\mathrm{C}_{4} \mathrm{AF}$ \\
\hline 64 & 13 & 6 & 12 \\
\hline
\end{tabular}

\subsection{Experimental Methods}

2.2.1. Physical and Rheological Properties. The measurements of cement setting time were tested using the Vicat apparatus. The setting behavior of cement added with SG curing in two different temperatures were tested. Specifically, the curing temperature regimes of cement pastes were $20^{\circ} \mathrm{C}$ and $35^{\circ} \mathrm{C}$, respectively; furthermore, the curing humidity conditions were both on $95 \%$. The setting time retention percentage of cement added with SG curing at $35^{\circ} \mathrm{C}$ was defined as follows:

$$
P_{r}(\%)=100 \times \frac{S_{(35)}}{S_{(20)}}(\%),
$$

where $P_{r}(\%)$ is the cement setting time retention percentage at $35^{\circ} \mathrm{C}, S_{(35)}$ is the cement setting time at $35^{\circ} \mathrm{C}$, and $S_{(20)}$ is the cement setting time at $20^{\circ} \mathrm{C}$. The values of $P_{r}$ were used to evaluate the temperature adaptability of SG. It meant that the greater the value was, the more excellent the temperature adaptability was.

The samples for investigating performance of compressive strength were prepared using the specimens with the size of $40 \mathrm{~mm} \times 40 \mathrm{~mm} \times 40 \mathrm{~mm}$. In this study, cement was prepared with combination of different dosages of SG (0.02 wt.\%, 0.06 wt.\%, 0.10 wt.\%, and 0.15 wt.\% by cement mass) and PCE (0.34 wt.\% by cement mass) for investigating pastes' fluidity. Mixing was immediately started after the addition of water and continued for $90 \mathrm{~s}$. Paste scaling on the vessel walls was scrapped off, and mixing was continued for another $90 \mathrm{~s}$. The cement pastes' fluidity was tested at $0 \mathrm{~min}$, $30 \mathrm{~min}, 60 \mathrm{~min}$, and $120 \mathrm{~min}$ after mixing, respectively, and the curing condition was under the temperature of $20^{\circ} \mathrm{C}$ and humidity of $95 \%$.

SG, deionized water, and cement were mixed in a mixer for $2 \mathrm{~min}$ to test the cement paste suspension zeta potential. And the selected cement paste was diluted 500 times by 
TABLE 3: Mix proportions of cement paste for physical and mechanical properties.

\begin{tabular}{lcccc}
\hline Properties & W/C & Curing temperature $\left({ }^{\circ} \mathrm{C}\right)$ & Dosages of SG $(w t . \%)$ & Dosages of PCE (wt.\%) \\
\hline Setting time & & 20 & $0.02,0.04,0.06,0.08,0.10,0.15,0.20,0.30,0.40$ & - \\
Compressive strength & 0.30 & 35 & $0.02,0.04,0.06,0.08,0.10,0.15,0.20$ & - \\
Cement pastes' fluidity & 20 & $0.02,0.06,0.10,0.15$ & 0.34 \\
Zeta potential & 20 & $0.02,0.06,0.10$ & - \\
\hline
\end{tabular}

mixing in a magnetic stirrer for $5 \mathrm{~min}$. The zeta potential of cement was measured by Zeta-Meter 3.0+ manufactured from Ankersmid, Netherlands. The mix proportions of physical and rheological properties are given in Table 3.

2.2.2. Hydration Heat Flow. The hydration heat flow of cement added with SG was carried out using the microcalorimeter with 8 channels (TAM air from TA instruments, United States) at a temperature of $20 \pm 1^{\circ} \mathrm{C}$. The cement heat flows were recording by using a computer, and the time span was ranging from $0 \mathrm{~h}$ to $168 \mathrm{~h}$.

2.2.3. XRD. The mix proportions of cement paste for XRD and TGA are shown in Table 4. XRD measurements were carried out on fresh slices before stopping hydration [21]. And the hydration of hardened cement pastes were stopped by absolute ethyl alcohol. The time for absolute ethyl alcohol to stop cement hydration was $1 \mathrm{~d}$ and $7 \mathrm{~d}$ for XRD analysis, respectively. XRD was used to quantify the crystalline phases present in the cement paste [22]. The data were collected using by using a Bruker D8 Advance Diffractometer $(\mathrm{CuK} \alpha, \lambda=1.54 \AA)$ operating in the Bragg-Brentano geometry on $40 \mathrm{kV}$ and $40 \mathrm{~mA}$. The XRD quantitifaction was studied by means of software MDI Jade 6.5 [23].

2.2.4. TGA. TGA was carried out with STA449C simultaneous thermal analyzer, and heating was carried out at a constant rate fixing as $15^{\circ} \mathrm{C} / \mathrm{min}$ from $25^{\circ} \mathrm{C}$ to $800^{\circ} \mathrm{C}$ in this study. In addition, $\mathrm{N}_{2}$ was used as shielding gas in the TGA test. The decomposition peak of $\mathrm{CH}$ in the hydrated cement system occurred between $420^{\circ} \mathrm{C}$ and $460^{\circ} \mathrm{C}$ in DTG curves. The $\mathrm{CH}$ amount could be calculated by using the following formula:

$$
\mathrm{CH}(\%)=\mathrm{WL}_{\mathrm{CH}}(\%) \frac{\mathrm{MW}_{\mathrm{CH}}}{\mathrm{MW}_{\mathrm{H}_{2} \mathrm{O}}} \text {, }
$$

where $\mathrm{WL}_{\mathrm{CH}}(\%)$ is the percentage of weight loss of $\mathrm{CH}$ and $\mathrm{MW}_{\mathrm{CH}}$ and $\mathrm{MW}_{\mathrm{H}}$ are the molecular weights of $\mathrm{CH}$ and $\mathrm{H}_{2} \mathrm{O}$, respectively [24].

\section{Results}

3.1. Setting Time. The setting time of cement pastes added with SG is given in Figure 2. The setting time of cement added with SG at the addition dosages ranging from $0.02 \%$ to $0.40 \%$ showed the tendency of gradual increasing. Furthermore, two good linear models $y=a \times x+b$ are fitted on these data to determine the relationship between the cement setting time and SG addition dosages when the
TABle 4: Mix proportions of cement paste for microanalyses.

\begin{tabular}{lcc}
\hline Samples & W/C & Dosage of SG (\%) \\
\hline Blank & & - \\
SG-2 & 0.02 \\
SG-6 & 0.30 & 0.06 \\
SG-10 & 0.10 \\
\hline
\end{tabular}

dosages ranged from $0.02 \%$ to $0.15 \%$. However, the final setting time of the cement added with SG at the dosages more than $0.15 \%$ sharply increases. To be specific, the interval time between initial time and final time even reaches over $60 \mathrm{~h}$ when the addition dosage was $0.40 \%$, and the interval time is too long.

Most researchers discuss that the setting time of cement added with retarders is measured at normal temperature, and the effect of SG on cement setting behavior at higher temperature was rarely discussed [25, 26]. The setting time retention percentage of cement added with $\mathrm{SG}$ is shown in Figure 3. It can be seen that the percentage presents gradual decreasing tendency with the increase in addition dosage. Specifically, the initial and finial setting time retention percentages are only $26.3 \%$ and $30.0 \%$, respectively, and at the dosage of $0.20 \%$, the values of percentage are far more less than the blank samples (75\%). It demonstrates that the environmental temperature has a great influence on the retarding effect of SG. And it cannot maintain the available retarding effect at higher temperature.

3.2. Compressive Strength. The compressive strength of cement added with SG is discussed in this part, and the results are given in Figure 4. The compressive strength of cement pastes added with different dosages of SG presents the tendency of increasing at first and then decreasing. The compressive strength is highest when the SG addition dosage is $0.06 \%$. Specifically, the $3 \mathrm{~d}$ and $28 \mathrm{~d}$ compressive strength at the addition dosage of $0.06 \%$ is even higher, i.e., $7.5 \mathrm{MPa}$ and $8.3 \mathrm{MPa}$, respectively, comparing to the blank sample. The $3 \mathrm{~d}$ compressive strength of cement pastes at the SG addition dosage more than $0.10 \%$ decreases sharply. In addition, the $3 \mathrm{~d}$ compressive strength is only $14 \%$ of the blank sample at the dosage of $0.20 \%$. The $28 \mathrm{~d}$ compressive strength at the addition dosages more than $0.15 \%$ is less than that of the blank sample. Specifically, the $28 \mathrm{~d}$ compressive strength is $75 \%$ of the blank sample at the dosage of $0.20 \%$. It shows that SG has positive effects on the compressive strength at dosage less than $0.15 \%$, and once this limitation dosage is exceeded, the negative effects occur [27]. 


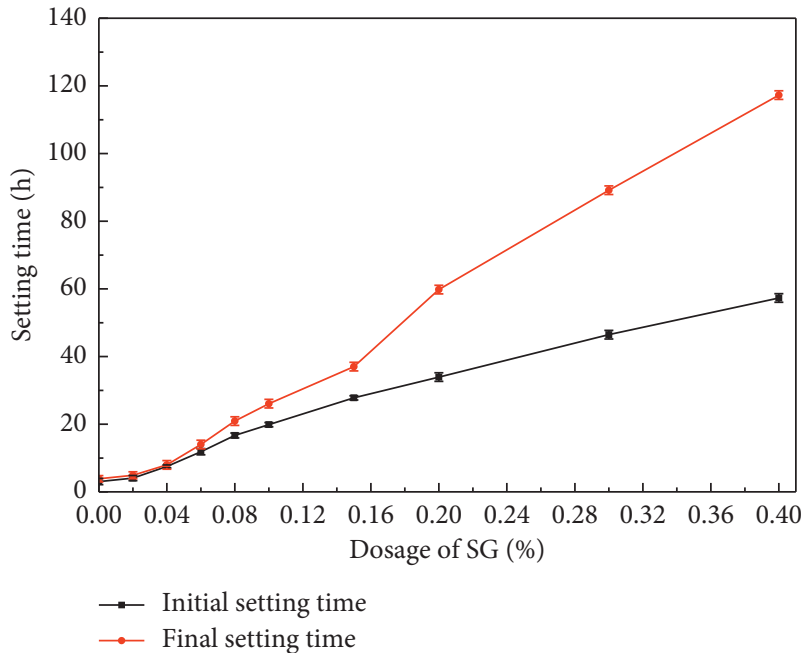

(a)

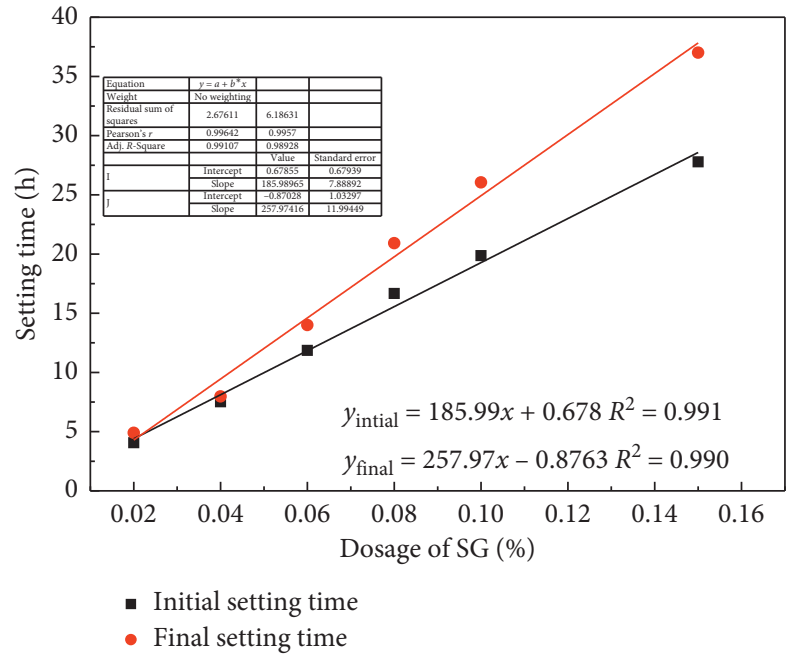

(b)

Figure 2: Setting time of cement pastes added with SG. (a) Setting time. (b) Fitting curve.

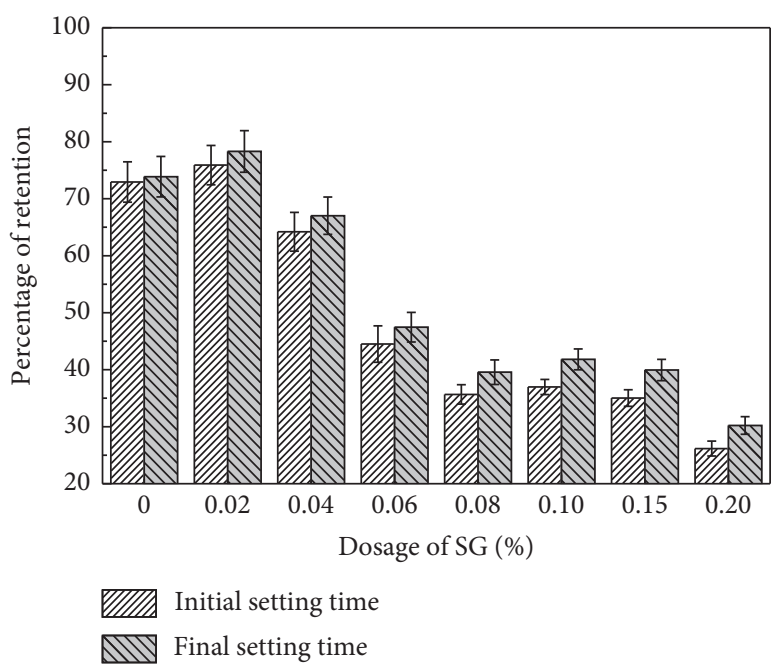

FIGURE 3: Setting time retention percentage of cement added with SG.

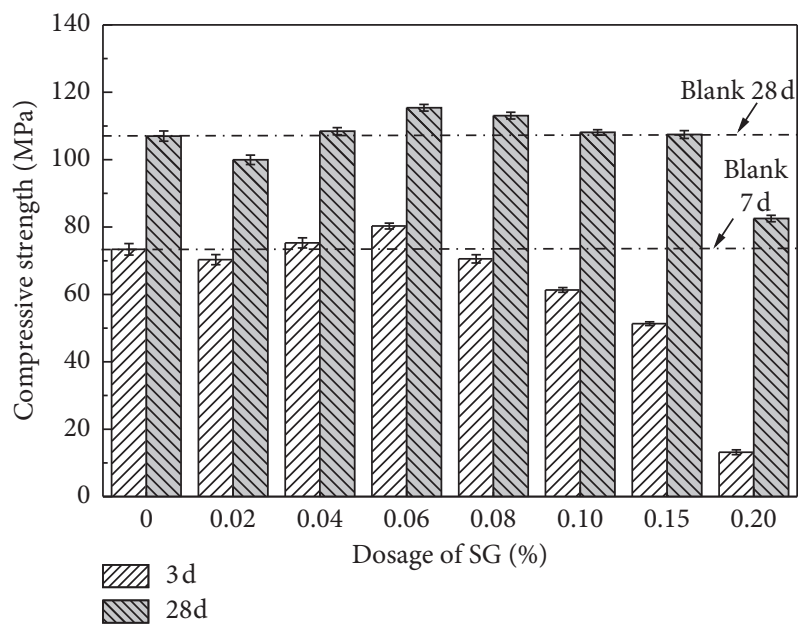

FIGURE 4: Compressive strength of cement pastes added with SG.
3.3. Fluidity. It is generally believed that the incorporation of SG can significantly enhance the dispersion ability of the cement-superplasticizer system [28, 29]. The influences of SG on fluidity of cement pastes' incorporation with PCE are discussed in this part, and the results are given in Figure 5. The fluidity of cement pastes presents reducing tendency as time goes by. The tendency of cement pastes' initial fluidity with SG dosages presents increasing trend at first and then the decreasing trend when the addition dosage is from $0 \%$ to $0.15 \%$. Meanwhile, the cement pastes' initial fluidity is largest when the addition dosage is $0.06 \%$. More importantly, the fluidity of paste added with $0.15 \%$ SG is less than the blank sample at different times. It shows that the dispersion behaviors of PCE-SG-cement system are decided by the addition dosage of SG. SG enhances the cement pastes' dispersion at lower dosages, whereas it generates negative effect on pastes' dispersion at higher dosages, and this phenomenon is consistent with the conclusion proposed by Zhang at al. [16]. It is attributed to the long side chain of PCE that may induce negative effects on the combination with SG, due to PCE with much bigger conformation size than carboxyl group in solution, and it can hinder the SG molecules from approaching to the carboxyl groups in PCE $[11,30]$.

3.4. Zeta Potential. Effect of SG on zeta potential of cement paste is presented in Figure 6. Zeta potential is generally used for investigating particle surface charge of cement adsorbed with admixtures [31,32]. The zeta potential of the blank sample is negative at the initial hydration time, and the absolute value is decreasing during $0 \mathrm{~min}-60 \mathrm{~min}$. It can be concluded that SG with negative charge is adsorbed on cement grains, and this insoluble layer of big SG ions hinders the access of water to the cement particles; thus, the zeta potential of samples added with SG remains negative during $0 \mathrm{~min}-60 \mathrm{~min}$ [33]. And then zeta potential becomes positive, and the absolute value shows increasing 


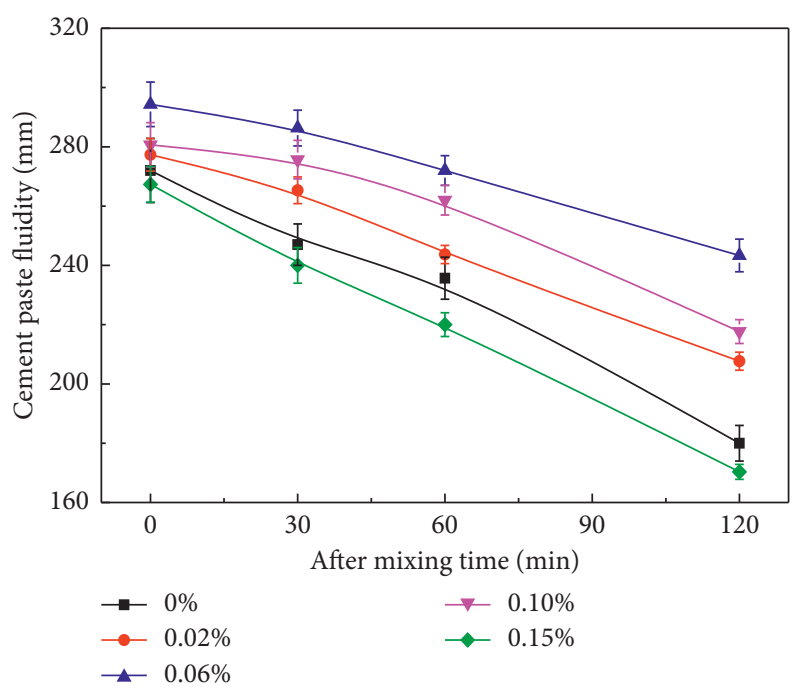

(a)

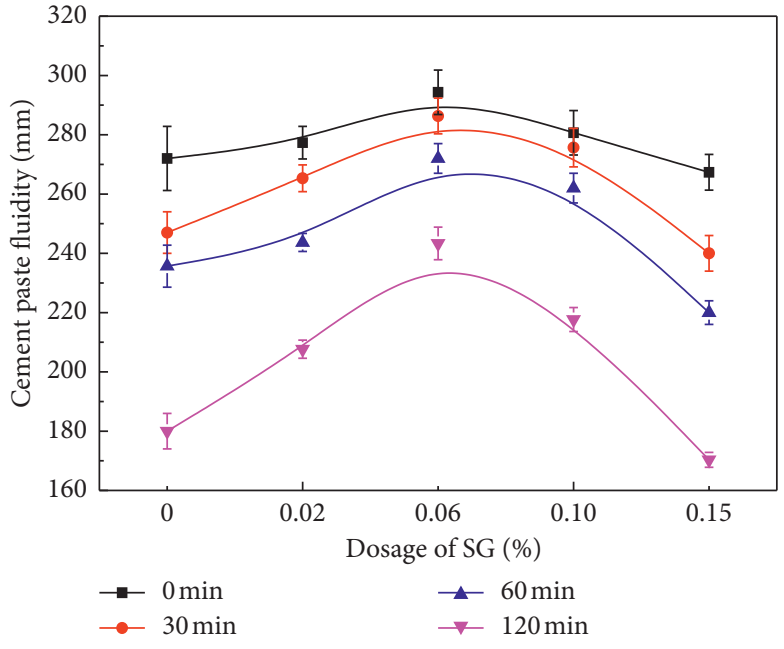

(b)

FIGURE 5: Influence of SG on cement pastes' fluidity. (a) Fluidity changes with time goes by. (b) Fluidity changes with the addition dosages.

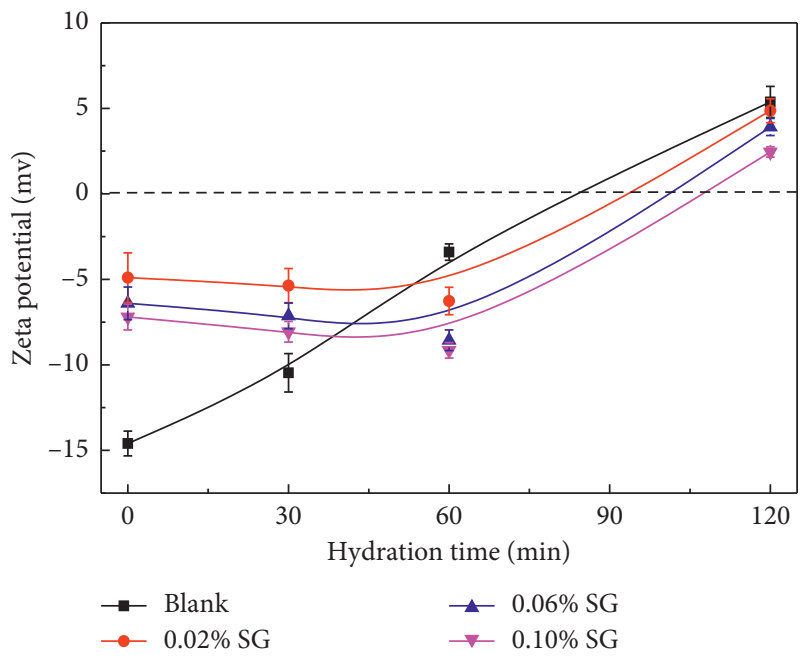

FIGURE 6: Effect of SG on zeta potential of cement paste.

trend constantly during $60-120 \mathrm{~min}$. It is because of the increase in $\mathrm{Ca} 2+$ concentration in pore solution of the blank sample; meanwhile, the resultant positive hydration products are encapsuled cement particle [34]. Furthermore, the cement particle surface charges become positive at the hydration of $120 \mathrm{~min}$. It is attributed that SG cannot prevent the cement hydration absolutely, and the hydration products with positive potential are formed and wraps up cement particles.

3.5. Hydration Heat Analysis. The curves for hydration heat and evolution rate of cement added with SG are shown in Figure 7. As seen in Figure 7(a), it is obvious that SG can reduce cumulative hydration heat at some degrees. Specifically, the cumulative hydration heat values during $168 \mathrm{~h}$ of sample SG-6 and sample SG-10 are 9.6\% and 4.5\% lower than the blank sample, respectively. The hydration cumulative heat of sample SG-6 is less than that of the sample SG-10 at the hydration time ranging from $0 \mathrm{~h}$ to $104.4 \mathrm{~h}$, but the cumulative heat of sample SG-10 exceeds that of the sample SG-6 when the hydration time is above 104.4 h. It can be seen from Figure 7(b), SG delays the occurrence time of the heat evolution peak. The heat evolution peak occurrence time of sample SG-6 and sample SG10 prolongs $29.4 \mathrm{~h}$ and $43.9 \mathrm{~h}$, respectively. In addition, the evolution rate peak values of sample SG-6 and sample SG-10 are $15.4 \%$ and $12.6 \%$ lower than the blank sample, respectively. It is very interesting that the value of the evolution rate peak of sample SG-10 is even higher than that of the sample SG-6.

3.6. XRD Analysis. The XRD patterns of hydrated cement with the addition of SG at $1 \mathrm{~d}$ and $7 \mathrm{~d}$ are exhibited in Figure 8. For further studying the diffraction peak characteristics, the integrated results of XRD diffraction peak of $\mathrm{CH}, \mathrm{Aft}$, and $\mathrm{C}_{3} \mathrm{~S}$ are investigated by software MDI Jade 6.5, and the results are shown in Tables 5-7, respectively. It is very interesting that the AFt amount of samples added with different dosages of SG shows very different trend. Specifically, the AFt amount of sample SG-6 is 1.51 times that of the blank sample at $1 \mathrm{~d}$. However, the AFt amount of sample SG-10 is only 0.40 times that of that blank sample at $1 \mathrm{~d}$. It indicates that SG plays different roles on AFt formation in the case of different dosage additions at induction period. SG promotes the AFt formation in the case of lower addition ( < $0.06 \%$ ) at the induction period, but it inhibits the $\mathrm{AFt}$ formation in the case of higher dosage.

As it can be seen in Table 6, SG inhibits the formation of $\mathrm{CH}$ at different degrees. It presents the tendency that the higher the addition dosage of SG, the more significant the effect of inhibiting the formation of $\mathrm{CH} . \mathrm{C}_{3} \mathrm{~S}$ is the main phase in ordinary Portland cement, and it is widely considered that $\mathrm{CH}$ is mainly formed from the hydration of $\mathrm{C}_{3} \mathrm{~S}$ 


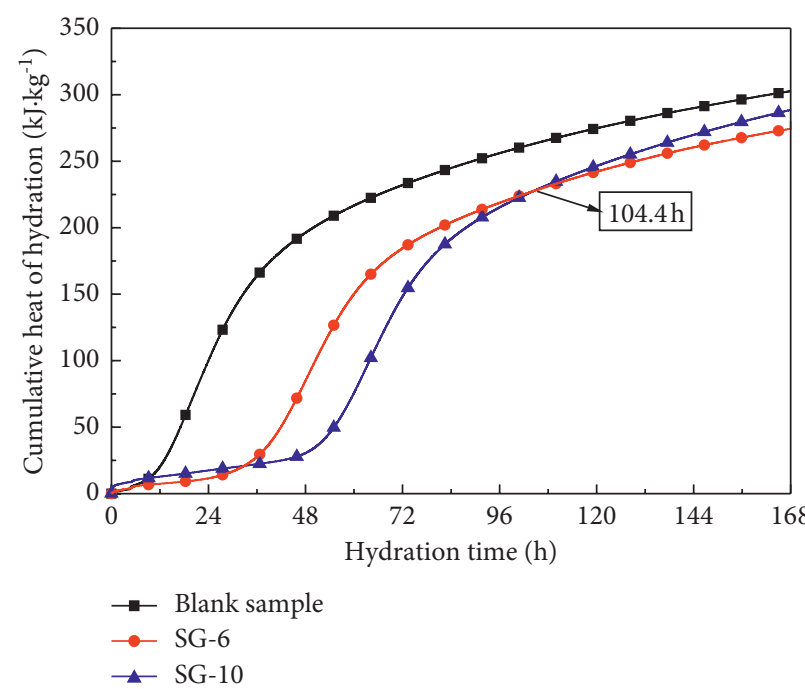

(a)

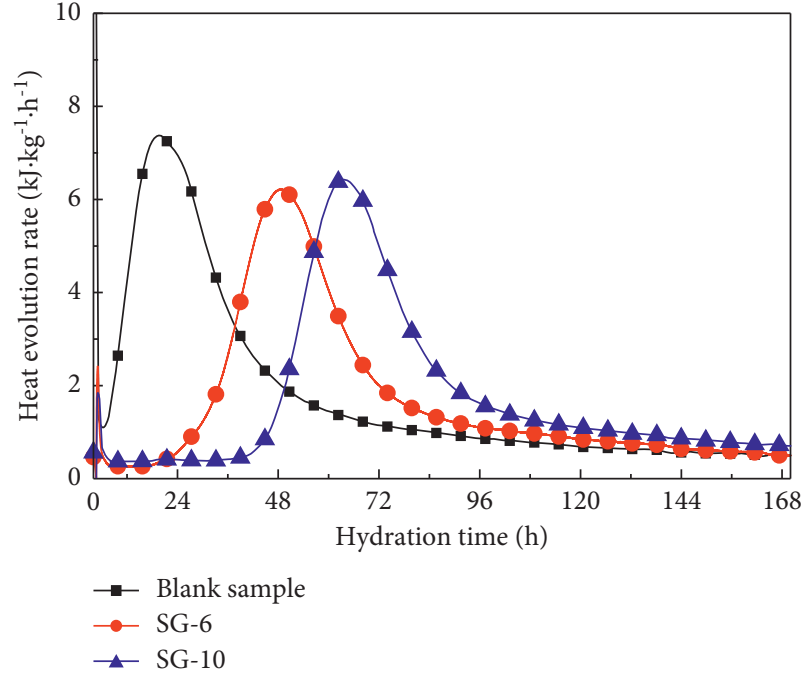

(b)

FIgURE 7: Curves of (a) cumulative hydration heat and (b) hydration heat evolution rate of cement added with SG.
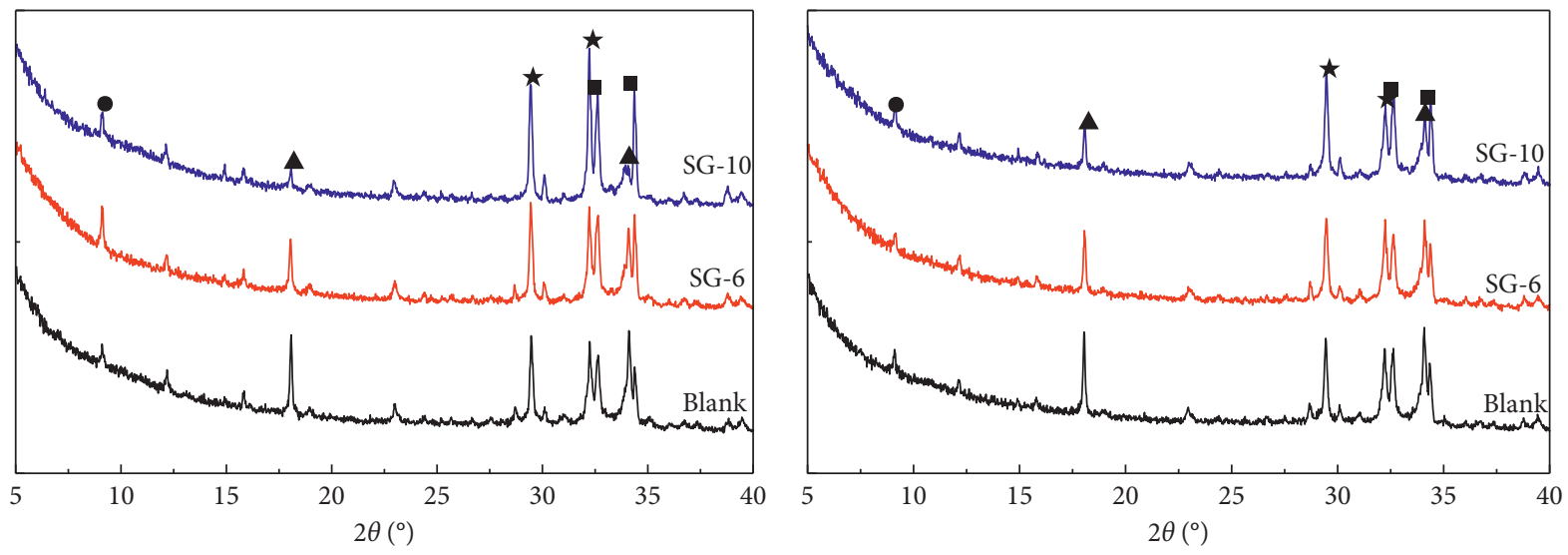

- $\mathrm{AFt}$

$\star \mathrm{C}_{3} \mathrm{~S}$

- $\mathrm{AFt}$

$\star \mathrm{C}_{3} \mathrm{~S}$

- $\mathrm{CH}$

(a)

(b)

FIGURE 8: XRD patterns of hydrated cement with the addition of SG. (a) $1 \mathrm{~d}$. (b) $7 \mathrm{~d}$.

TABLE 5: The integrated results of XRD diffraction peak of $\mathrm{AFt}$ corresponding to $2 \theta$ range of $9.0^{\circ}-9.5^{\circ}$.

\begin{tabular}{lccccc}
\hline Samples & $\begin{array}{c}\text { Hydration time } \\
(\mathrm{d})\end{array}$ & $\begin{array}{c}d \text { value } \\
(\AA)\end{array}$ & $\begin{array}{c}\text { FWHM } \\
\left({ }^{\circ}\right)\end{array}$ & Height & Area \\
\hline \multirow{2}{*}{ Blank } & 1 & 9.7069 & 0.099 & 374 & 2245 \\
& 7 & 9.7061 & 0.123 & 208 & 1544 \\
\hline \multirow{2}{*}{ SG-6 } & 1 & 9.7054 & 0.139 & 403 & 3398 \\
& 7 & 9.7095 & 0.138 & 186 & 1551 \\
\hline \multirow{2}{*}{ SG-10 } & 1 & 9.6893 & 0.070 & 213 & 900 \\
& 7 & 9.7059 & 0.109 & 170 & 1127 \\
\hline
\end{tabular}

TABLE 6: The integrated results of XRD diffraction peak of $\mathrm{CH}$ corresponding to $2 \theta$ range of $17.0^{\circ}-19.0^{\circ}$.

\begin{tabular}{lccccc}
\hline Samples & $\begin{array}{c}\text { Hydration time } \\
(\mathrm{d})\end{array}$ & $\begin{array}{c}d \text { value } \\
(\AA)\end{array}$ & $\begin{array}{c}\text { FWHM } \\
\left({ }^{\circ}\right)\end{array}$ & Height & Area \\
\hline \multirow{2}{*}{ Blank } & 1 & 4.9088 & 0.151 & 692 & 6339 \\
& 7 & 4.9134 & 0.155 & 719 & 6744 \\
\hline \multirow{2}{*}{ SG-6 } & 1 & 4.9134 & 0.175 & 480 & 5082 \\
& 7 & 4.9037 & 0.153 & 549 & 5277 \\
\hline \multirow{2}{*}{ SG-10 } & 1 & 4.9083 & 0.204 & 179 & 2206 \\
& 7 & 4.9036 & 0.146 & 414 & 3659 \\
\hline
\end{tabular}


TABLE 7: The integrated results of XRD diffraction peak of $\mathrm{C}_{3} \mathrm{~S}$ corresponding to $2 \theta$ range of $31.5^{\circ}-32.5^{\circ}$.

\begin{tabular}{|c|c|c|c|c|c|}
\hline Samples & Hydration time (d) & $d$ value $(\AA)$ & FWHM $\left(^{\circ}\right)$ & Height & Area \\
\hline \multirow{2}{*}{ Blank } & 1 & 2.7743 & 0.285 & 682 & 11773 \\
\hline & 7 & 2.7773 & 0.291 & 633 & 11152 \\
\hline \multirow{2}{*}{ SG-6 } & 1 & 2.7758 & 0.247 & 788 & 11791 \\
\hline & 7 & 2.7729 & 0.267 & 672 & 10866 \\
\hline \multirow{2}{*}{ SG-10 } & 1 & 2.7758 & 0.202 & 1327 & 16199 \\
\hline & 7 & 2.7741 & 0.287 & 607 & 10546 \\
\hline
\end{tabular}

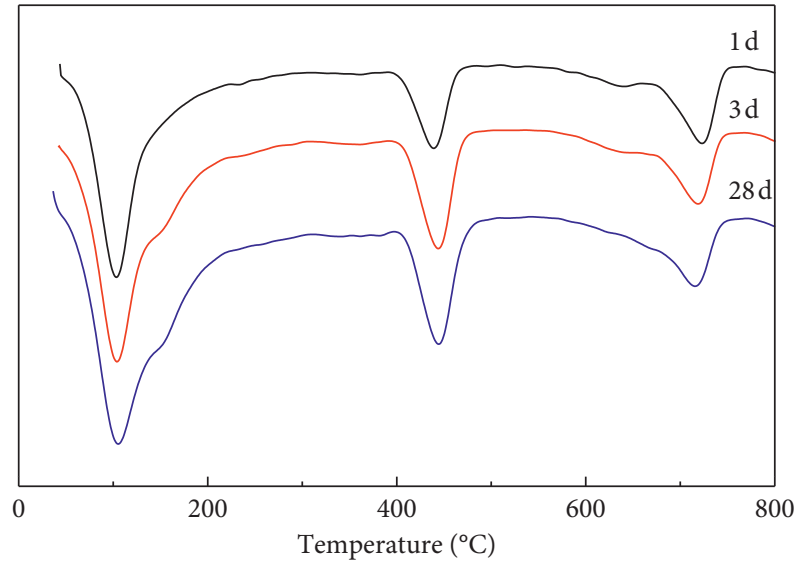

(a)

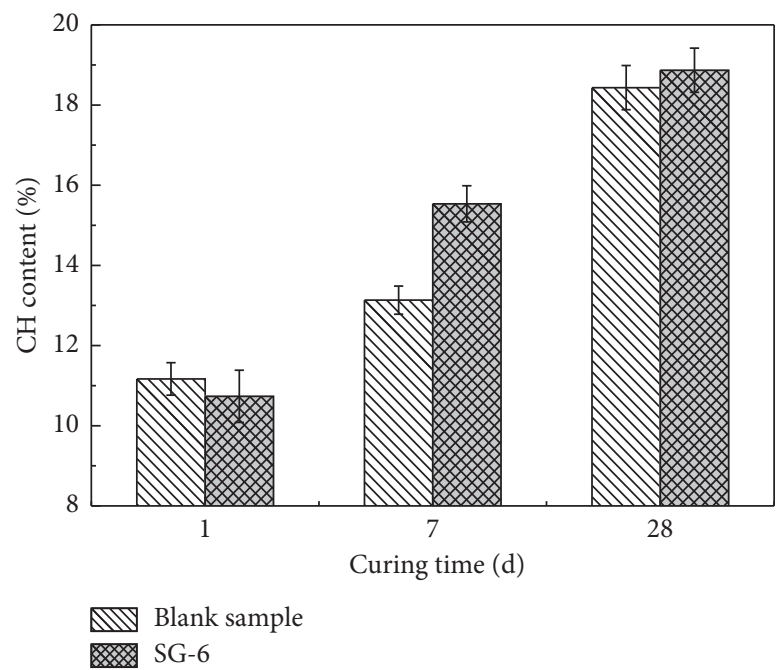

(b)

Figure 9: Results of DTG. (a) DTG curves of sample SG-6. (b) CH content in hydrated cement pastes.

[35]. Similarly, the amount of unhydrated $\mathrm{C}_{3}$ S presents very different trend at different hydration time. Specifically, the $\mathrm{C}_{3} \mathrm{~S}$ amount of the blank sample is 0.99 times and 0.73 times of sample SG-6 and sample SG-10, respectively, at $1 \mathrm{~d}$. Nevertheless, this ratio values become equivalent to 1.03 times and 1.06 times, respectively, at $7 \mathrm{~d}$. It indicates that SG inhibits hydration of $\mathrm{C}_{3} \mathrm{~S}$ at early hydration process $(<1 \mathrm{~d})$, but it promotes $\mathrm{C}_{3} \mathrm{~S}$ hydration when the hydration time is beyond $1 \mathrm{~d}$. At the same time, the higher the dosage of SG addition, the more significant promotion of $\mathrm{C}_{3} \mathrm{~S}$ hydration when the hydration time is beyond $1 \mathrm{~d}$.

3.7. Thermogravimetry Analysis. The DTG curves and the content of $\mathrm{CH}$ in hydrated cement pastes are discussed in this part, and the results are given in Figure 9. It can be seen in Figure 9(b) that the amount of $\mathrm{CH}$ in the blank sample is more than that of the sample SG-6 at $1 \mathrm{~d}$, but the amount of $\mathrm{CH}$ in the blank sample is less than that of the sample SG-6 at $7 \mathrm{~d}$ and $28 \mathrm{~d}$. To be more specific, the amounts of $\mathrm{CH}$ in blank sample are 1.04 times, 0.85 times, and 0.98 times that of SG-6 sample at $1 \mathrm{~d}, 7 \mathrm{~d}$, and $28 \mathrm{~d}$, respectively. It once again shows that SG inhibits the $\mathrm{CH}$ formation at early hydration process $(<1 \mathrm{~d})$; instead, it promotes the $\mathrm{CH}$ formation during $1 \mathrm{~d}$ to $7 \mathrm{~d}$. It also means that $\mathrm{SG}$ promotes the hydration of $\mathrm{C}_{3} \mathrm{~S}$ when the hydration time is beyond $1 \mathrm{~d}$. This result is consistent with the conclusion of XRD analysis in Section 3.6.

\section{Discussion}

According to the results of hydration behavior study above, the effect of SG on cement hydration behavior is complex. The roles of SG play on cement hydration depend on both the hydration time and the addition dosage of SG. SG inhibits the hydration of $\mathrm{C}_{3} \mathrm{~S}$ and the formation of $\mathrm{CH}$ at the early hydration period. However, it promotes the $\mathrm{C}_{3} \mathrm{~S}$ hydration when hydration time is beyond $1 \mathrm{~d}$. Meanwhile, the higher the addition dosage of SG, the more significant the promotion of $\mathrm{C}_{3} \mathrm{~S}$ hydration when the hydration time is beyond $1 \mathrm{~d}$.

At the same time, SG promotes the AFt formation in the case of lower addition $(<0.06 \%)$ at the induction period, but it inhibits the AFt formation in the case of higher dosage ( $>$ $0.06 \%)$. Based on this property of SG, the fluidity and mechanical performance of cement pastes added with SG also depend on the addition dosage. The initial fluidity and the fluidity loss of the cement pastes at the dosage of $0.06 \%$ exhibit the most outstanding performance in this study. However, some negative impacts on cement pastes' fluidity occur at the addition dosage more than $0.06 \%$.

This study only refers to the study on the effects of SG on hydration behavior of ordinary Portland cement. And many mechanisms are still unclear, such as the mechanism of drastic retarding effect of SG at higher temperature, the AFt formation mechanism at initial hydration age $(<30 \mathrm{~min})$ in 
the case of different addition dosages, and the adsorption kinetics of SG.

\section{Conclusions}

(1) The setting time and dosage of cement pastes added with SG present good linear relationship at the dosages ranging from $0.02 \%$ to $0.15 \%$ curing in the temperature of $20^{\circ} \mathrm{C}$. SG is difficult to maintain significant retarding effect at higher temperature $\left(>35^{\circ} \mathrm{C}\right)$.

(2) SG is able to reduce the cement cumulative hydration heat and delay the occurrence time of heat evolution peak at some degrees, but it has little impact on reducing the cement evolution rate peak. The mechanical and dispersion properties of cement pastes added with SG are depending on their additions. SG has positive effects on the compressive strength at the dosage less than $0.15 \%$, and the negative effects occur if the dosages exceed the limitation dosage.

(3) SG plays different roles on cement hydration in the case of different hydration time and different addition dosages. That is to say, SG inhibits the hydration of $\mathrm{C}_{3} \mathrm{~S}$ and the formation of $\mathrm{CH}$ at the early hydration period. But it promotes the $\mathrm{C}_{3} \mathrm{~S}$ hydration when hydration time is beyond $1 \mathrm{~d}$. Similarly, SG promotes AFt formation in the case of lower addition $(<0.06 \%)$ at the induction period, but it inhibits the AFt formation in the case of higher dosage $(>0.06 \%)$.

(4) The retarding effect of SG on cement hydration in this study may be ascribed by mineral surface adsorption and poisoning on the nucleation and growth of $\mathrm{CH}$. The accelerated AFt formation in the case of lower addition of SG can be attributed to the sulfate ions' promotion to react with $\mathrm{C}_{3} \mathrm{~A}$ [20].

The mechanism of hydration behavior of cement added with SG, i.e., depending on hydration time and the SG addition dosages, will deeply be investigated in the future studies. The effects of SG on cement minerals', $\mathrm{C}_{3} \mathrm{~S}$ and $\mathrm{C}_{3} \mathrm{~A}$, hydration will also be deeply investigated in the future studies. It will focus on the effects of $\mathrm{SG}$ on $\mathrm{C}_{3} \mathrm{~S}$ and $\mathrm{C}_{3} \mathrm{~A}$ hydration product types, amounts, space distribution, and microstructure.

\section{Data Availability}

The authors declare the data used to support the findings of this study are available from the corresponding author upon request.

\section{Conflicts of Interest}

The authors declare that they have no conflicts of interest.

\section{Acknowledgments}

The authors gratefully acknowledge the support from the National Key R\&D Program of China (2016YFB0303601),
National Natural Science Foundation of China (51579019, 51779019, and 51809017), the Central Non-Profit Scientific Research Fund for Institutes (grant no. CKSF2019200/CL), and China Three Gorges Corporation Research Project (BHT0807).

\section{References}

[1] B. Li, X. Lv, W. Yunquan, and J. Zhang, "Effect of amino trimethylene phosphonic acid on hydration of portland cement," Journal of Building Materials, vol. 19, no. 3, pp. 417423, 2016, in Chinese.

[2] J. Rickert and G. Thielen, "Influence of a long-term retarder on the hydration of clinker and cement," Cement Concrete Aggregate, vol. 26, no. 2, pp. 92-101, 2004.

[3] K. Yang, C. Zhang, Y. Guo, and Z. Llu, "Study on retarding the set of sulphoaluminate cement," Journal of the Chinese Society, vol. 30, no. 2, pp. 155-160, 2002, in Chinese.

[4] X. Kong, Z. Lu, J. Shi, D. Wang, S. Hou, and H. Liu, "Impacts of phosphoric acid and phosphates on hydration kinetics of Portland cement," Journal of the Chinese Society, vol. 40, no. 11 , pp. 1553-1558, 2012, in Chinese.

[5] A. Peschard, A. Govin, J. Pourchez et al., "Effect of polysaccharides on the hydration of cement suspension," Journal of the European Ceramic Society, vol. 26, no. 8, pp. 1439-1445, 2006.

[6] T. Pyatina and T. Sugama, “"High-temperature alkaline stability of cement set retarders and their performance at 70-90 C," Advances in Cement Research, vol. 25, no. 6, pp. 25-35, 2013.

[7] G. Li, T. He, and Y. Wu, "Effect of sodium gluconate on the fluidity and flow loss of pastes with $\beta$-naphthalenesulfonic acid-based superplasticizer," Journal of the Chinese Society, vol. 38, no. 4, pp. 768-773, 2010, in Chinese.

[8] J. Cheung, A. Jeknavorian, L. Roberts, and D. Silva, "Impact of admixtures on the hydration kinetics of Portland cement," Cement and Concrete Research, vol. 41, no. 12, pp. 1289-1309, 2011.

[9] F. Zou, H. Tan, Y. Guo, B. Ma, X. He, and Y. Zhou, "Effect of sodium gluconate on dispersion of polycarboxylate superplasticizer with different grafting density in side chain," Journal of Industrial and Engineering Chemistry, vol. 55, pp. 91-100, 2017.

[10] G. Li, Y. Li, C. Shi, Q. Wang, and C. Chen, "Influence of retarder on the fluidity and strength of the sulphate aluminium cement paste containing naphthalene based superplasticizer," Bulletin of the Chinese Ceramic Society, vol. 33, no. 12, pp. 3295-3299, 2014.

[11] B. Ma, G. Li, X. Li et al., "Study on the effects by compounding the polycarboxylic type superplasticizer with sodium gluconate," Journal of Wuhan University of Technology, vol. 33, no. 1, pp. 52-55, 2011.

[12] H. Tan, F. Zou, B. Ma, Y. Guo, X. Li, and J. Mei, "Effect of competitive adsorption between sodium gluconate and polycarboxylate superplasticizer on rheology of cement paste," Construction and Building Materials, vol. 144, pp. 338-346, 2017.

[13] S. Ma, W. Li, S. Zhang, D. Ge, J. Yu, and X. Shen, "Influence of sodium gluconate on the performance and hydration of portland cement," Construction and Building Materials, vol. 91, no. 5, pp. 138-144, 2015.

[14] E. E. Hekal and E. A. Kishar, "Effect of sodium salt of naphthalene-formaldehyde polycondensate on ettringite 
formation," Cement and Concrete Research, vol. 29, no. 10, pp. 1535-1540, 1999.

[15] M. Bishop and A. R. Barron, "Cement hydration inhibition with sucrose, tartaric acid, and lignosulfonate: analytical and spectroscopic study," Industrial \& Engineering Chemistry Research, vol. 45, no. 21, pp. 7042-7049, 2006.

[16] X. Zhang, Y. He, C. Lu, and Z. Huang, "Effects of sodium gluconate on early hydration and mortar performance of Portland cement-calcium aluminate cement-anhydrite binder," Construction and Building Materials, vol. 157, pp. 1065-1073, 2017.

[17] J. P. Perez, "The mechanism of action of sodium gluconate on the fluidity and set of portland cement," in Proceedings of the 12th International Congress on the Chemistry of Cement, Montreal, Canada, July 2007.

[18] H. von Daake and D. Stephan, "Impact of retarders by controlled addition on the setting, early hydration and microstructural development of different cements," Magazine of Concrete Research, vol. 68, no. 19, pp. 1011-1024, 2016.

[19] B. Ma, G. Li, X. Li et al., "Study on the effects by compounding the polycarboxylic type superplasticizer with sodium gluconate," Journal of Wuhan University of Technology, vol. 33, no. 1 , pp. 50-53, 2011, in Chinese.

[20] Y. Wu, T. He, F. Shen et al., "Influences of the compounding of sodium gluconate with superplasticizer on the process of cement hydration," Journal of Xi'an University of Architect \&Technology (Natural Science Edition), vol. 40, no. 6, pp. 806-809, 2008, in Chinese.

[21] W. Huang, H. Kazemi-Kamyab, W. Sun, and K. Scrivener, "Effect of cement substitution by limestone on the hydration and microstructural development of ultra-high performance concrete (UHPC)," Cement and Concrete Composites, vol. 77, pp. 86-101, 2017.

[22] V. Shah, K. Scrivener, B. Bhattacharjee, and S. Bishnoi, "Changes in microstructure characteristics of cement paste on carbonation," Cement and Concrete Research, vol. 109, pp. 184-197, 2018.

[23] R. Wang, X.-G. Li, and P.-M. Wang, "Influence of polymer on cement hydration in SBR-modified cement pastes," Cement and Concrete Research, vol. 36, no. 9, pp. 1744-1751, 2006.

[24] A. Peschard, A. Govin, P. Grosseau, B. Guilhot, and R. Guyonnet, "Effect of polysaccharides on the hydration of cement paste at early ages," Cement and Concrete Research, vol. 34, no. 11, pp. 2153-2158, 2004.

[25] A. Salahaldein, "Effects of super plasticizing and retarding admixtures on properties of concrete," in Proceedings of the International Conference on Innovations in Engineering and Technology, pp. 271-274, Seoul, South Korea, November 2013.

[26] B. Li, X. Lv, Y. Dong, S. Zhou, and J. Zhang, "Comparison of the retarding mechanisms of sodium gluconate and amino trimethylene phosphonic acid on cement hydration and the influence on cement performance," Construction and Building Materials, vol. 168, pp. 958-965, 2018.

[27] X. Lv, B. Li, Y. Shi et al., "Comparison of the influence of amino trimethylene phosphonic acid and sodium gluconate on the performance of concrete," in Proceedings of the International Conference on Architectural, Civil and Hydraulics Engineering, vol. 44, pp. 1-8, Guangzhou, China, November 2015.

[28] T. He, F. Shen, and F. C. Wang, "Influences of combination of superplasticizers and retarders on process of cement hydration," Journal of Chinese Ceramic Society, vol. 35, no. 6, pp. 796-800, 2007, in Chinese.
[29] G. Zhang, G. Li, and Y. Li, "Effects of superplasticizers and retarders on the fluidity and strength of sulphoaluminate cement," Construction and Building Materials, vol. 126, pp. 44-54, 2016.

[30] F. Dalas, S. Pourchet, A. Nonat, D. Rinaldi, S. Sabio, and M. Mosquet, "Fluidizing efficiency of comb-like superplasticizers: the effect of the anionic function, the side chain length and the grafting degree," Cement and Concrete Research, vol. 71, pp. 115-123, 2015.

[31] J. Plank and C. Hirsch, "Impact of zeta potential of early cement hydration phases on superplasticizer adsorption," Cement and Concrete Research, vol. 37, no. 4, pp. 537-542, 2007.

[32] S. Srinivasan, S. A. Barbhuiya, D. Charan, and S. P. Pandey, "Characterising cement-superplasticiser interaction using zeta potential measurements," Construction and Building Materials, vol. 24, no. 12, pp. 2517-2521, 2010.

[33] W. Kurdowski, Cement and Concrete Chemistry, Springer, Berlin, Germany, 2014.

[34] L. Nachbaur, P.-C. Nkinamubanzi, A. Nonat, and J.-C. Mutin, "Electrokinetic properties which control the coagulation of silicate cement suspensions during early age hydration," Journal of Colloid and Interface Science, vol. 202, no. 2, pp. 261-268, 1998.

[35] K. O. Kjellsen and B. Lagerblad, "Microstructure of tricalcium silicate and portland cement systems at middle periods of hydration-development of Hadley grains," Cement and Concrete Research, vol. 37, no. 1, pp. 13-20, 2007. 